\title{
Imagem e Desejo
}

Image and Desire

DOI: 10.20396/rhac.v2i2.15274

PABLO CAYUQUEO

Investigador independente

(D) 0000-0002-0383-5965

SAMUEL QUIROGA

Investigador independente

(D) 0000-0002-0383-5965

\section{Resumo}

A partir da tensão entre o desejo sexual e suas práticas reguladas pelo poder, analisamos a função dos dispositivos que disciplinam e domesticam os corpos, que, a nosso ver, se instalam segundo os interesses dos grupos hegemônicos: a produção e a acumulação capitalista. Como esse disciplinamento forçou uma ordem cultural que castiga as manifestações sexuais dissidentes? Respondemos a essa pergunta revelando dispositivos visuais que desafiam uma hegemonia heteronormativa que não apenas subjuga os corpos, mas também reprime toda alteridade que não adere às suas imposições. Esta análise se apoia em uma estrutura conceitual que chamamos de "teoria quiltra".

Palavras-chave: Heteronorma. Conhecimento subordinado. Dissidência. Camp. Kuir.

\begin{abstract}
From the tension between sexual desire and its practices regulated by power, we analyze the function of the devices that discipline and domesticate bodies, which, in our view, are installed according to the interests of hegemonic groups: the production and accumulation of capitalists. How has this discipline forced a cultural order that punishes divergent sexual manifestations? We answer this question by revealing visual devices that challenge a heteronormative hegemony that not only subjugates bodies, but also represses any otherness that does not adhere to its impositions. This analysis is supported by a conceptual framework that we call the "quiltra theory".
\end{abstract}

Keywords: Heteronorm. Subordinate knowledge. Dissent. Camp. Kuir. 


\section{Introdução'}

A arte, assim como a literatura ou os meios de comunicação, são campos de produção de bens e imaginários culturais. Para exercer a dominação, os grupos mais poderosos utilizam todos os dispositivos que dispõem: o Estado, os políticos, os militares, a polícia, o espetáculo, a arte, etc. "El Arte, escrita la palabra con A mayúscula, no existe, pues el Arte con A mayúscula tiene por esencia que ser un fantasma y un ídolo"2. No sistema capitalista ocidental, a cultura afirmativa é um mecanismo de construção da hegemonia, onde a imagem é um dispositivo crucial na construção de subjetividades que legitimem a dominação. ${ }^{3}$ Isso explica a razão das hierarquias e estratificações que ocorrem na Arte. Todos os dispositivos normativos, incluindo discursos e imagens, afetam até mesmo a maneira como movemos o corpo. No entanto, é conveniente enfatizar que, embora o uso e a valorização da imagem criada pelo artista dependam de quão regulada e institucionalizada esteja, o poder nem sempre pode controlar todos os espaços nem todas as ações que ocorrem nos territórios que domina.

Na modernidade colonialista-capitalista, os sistemas conceituais não são uma tecnologia neutra, mas em muitos casos um dispositivo de normalização e subjetivação do corpo, do espaço e das expressões culturais. É a partir dessas ideias que as segmentações de sexo, gênero, raça, classe, etc. são inventadas e reproduzidas. E muitas vezes estas são fixadas como uma cerca invisível que limita a livre movimentação dos corpos. É por isso que, seguindo a intelectual muçulmana Sirin Adlbi Sibai, ${ }^{4}$ somos mobilizados por um impulso que nos faz querer fugir do que ela chama de prisão epistemológica centrada no Ocidente. Não negamos os sistemas conceituais europeus, apenas desconfiamos. Seguindo as palavras de Audre Lord, quando afirma que "las herramientas del amo nunca desmontan la casa del amo", ${ }^{5}$ nossa desconfiança provém da suspeita de que os conceitos teóricos nem sempre têm como objetivo acabar com a dominação. Consequentemente, acreditamos que é importante forçar as construções teóricas para resgatar o que nos serve na emancipação e nos defender daqueles que quer nos levar de volta à prisão epistemológica. Por enquanto, não queremos descartar todos os conceitos teóricos do homem branco, o que buscamos é elaborar, mesmo que seja a partir de fragmentos, um sistema teórico mestiço que nos sirva de escape.

Nosso pensamento é situado, mas não é imóvel nem inalterável; é bastante nômade. Discordamos do binômio centro/periferia, daquele olhar ocidental cuja política colonial se baseia na

\footnotetext{
'Tradução ao português de Anna Paula Duarte.

${ }^{2}$ GOMBRICH, Ernst. La historia del arte. Phaidon, 1997, p. 15.

${ }^{3}$ Cf.: MARCUSE, Herbert. Cultura y sociedad. Buenos Aires: Sur, 1978

${ }^{4}$ ADLBI SIBAI, Sirin. La cárcel del feminismo. Hacia un pensamiento islámico decolonial. México: Akal, 2017.

${ }^{5}$ LORDE, Audre. La hermana, la extranjera. Madrid: horas y HORAS, la editorial, 2003, p. 115.
} 
exclusão do "outro". O Ocidente é a nossa periferia, pois acreditamos que é preciso pensar, criar e introduzir metodologias mestiças e saberes subalternos; associar-nos a outros corpos num movimento anticolonial, consciente e crítico do peso que tem um legado colonial que ainda hoje condiciona as nossas sociedades ocidentalizadas. Nossas coordenadas epistêmicas adaptam-se ao território onde nos movemos, vivemos, sentimos e interagimos. Nessa vasta paisagem cultural, onde convivem nossos corpos mestiços, índios, negros, mulatos e pardos, como um todo subalterno, nosso norte é o sul, como apontava Joaquín Torres-Carcía em 1943 [Figura 1]. Consequentemente, neste texto tratamos de expressões culturais visuais que evidenciam a desobediência dos corpos e sua resistência às práticas sexuais heteronormativas.

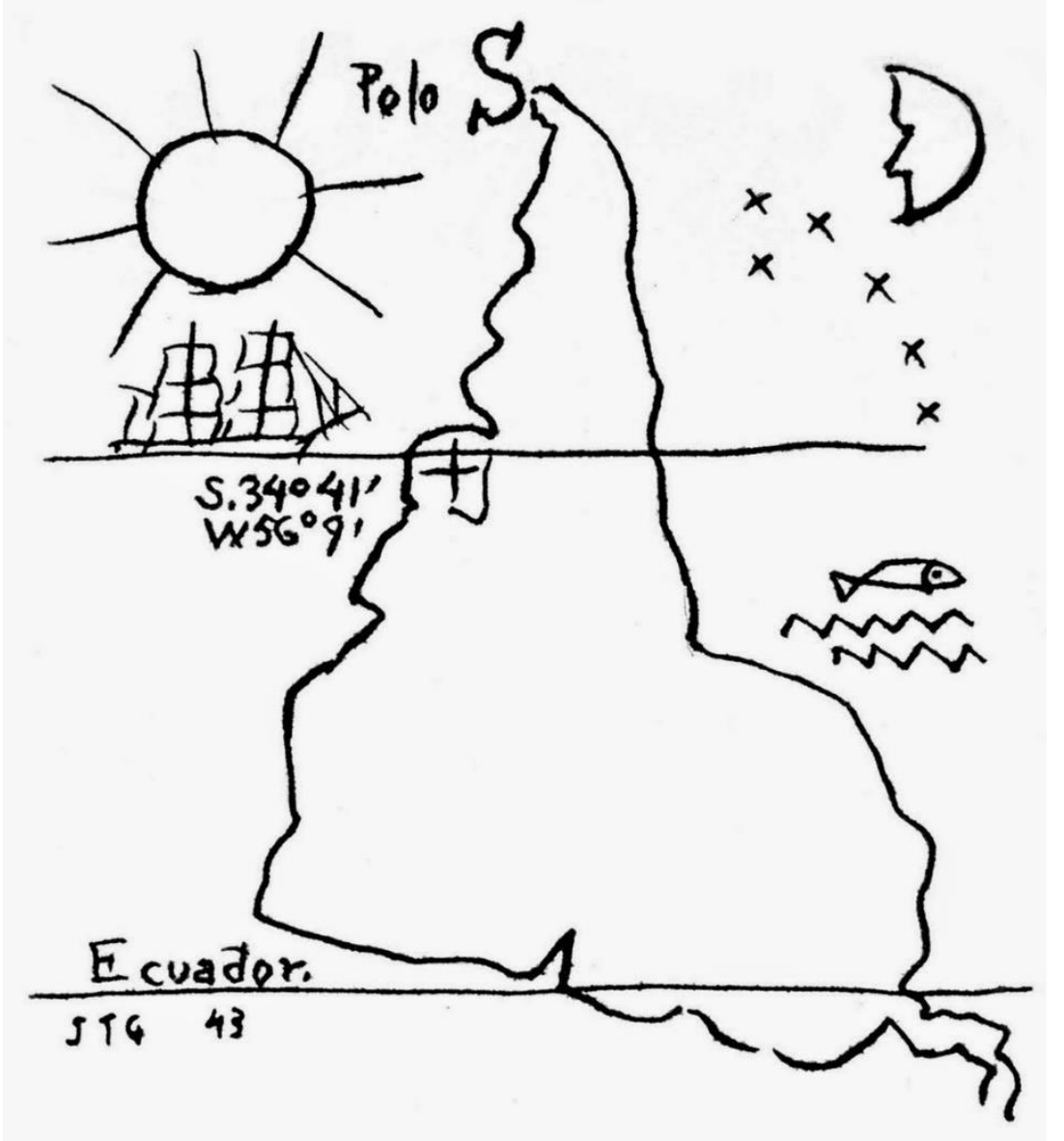

Figura 1:

Joaquín Torres García (Montevideo, Uruguay, 1874-1949)

América invertida 
Não nos interessa forçar os objetos a serem estudados dentro de um marco teórico rígido e acabado, mas sim buscar os conceitos que melhor se adaptam aos fenômenos que queremos explicar. $\mathrm{O}$ resultado é uma seleção de categorias que juntas formam o que chamamos de "teoria quiltra". Ao analisar nossa paisagem cultural, com suas particularidades e complexidades, não podemos ignorar que a colonialidade ocidental atravessa nossos corpos quiltros. No Chile, um quiltro é um cão de raça mista, ou sem raça definida que não pertence a nenhuma raça reconhecida, não tem pedigree e nem é conhecido por ter qualquer ascendência. ${ }^{6}$ Um quiltro não é produto do planejamento humano, ele se forma nos códigos da rua, não segue a norma e não gostam de usar coleira. No campo das ideias, essas características do quiltro são valiosas, pois, além de nos identificarmos com suas características, nos permitem transitar e adaptar categorias de diversos campos teóricos e utilizá-las como armas-ferramentas na análise, sem lealdades nem devoções a nenhum dogma. Acreditamos que a teoria do quiltra nos dá maiores possibilidades de libertação e independência na elaboração de cartografias que nos auxiliem na compreensão do mundo. Não nos interessa militar em um determinado dogma teórico; ao contrário, buscamos armas para escapar daqueles conhecimentos episteme que com suas doutrinas e certezas nos usam como recursos, para nos domesticar, civilizar e eliminar.

As histórias e/ou memórias são um campo em disputa, e não apenas entre as elites hegemônicas, uma vez que vários grupos subalternos foram incorporados ao longo do século XX. Esses corpos críticos de operações que atravessam a produção cultural, política e social, gradualmente ganham espaço a partir da criação de dispositivos contra-hegemônicos cujos significantes culturais e identitários se expressam em termos estético-políticos. As lutas culturais como as indígenas, sexuais, de gênero, as que promovem a autodeterminação das mulheres, as que defendem o aborto livre, as que reivindicam etnias, as que questionam a racialização, as que visibilizam a AIDS ou promovem os direitos dos animais, são apenas alguns exemplos onde os corpos subalternizados buscam a emancipação das taxonomias impostas pelas epistemes que nos subjugam e marginalizam.

Quem se rebela contra os axiomas do conhecimento atenta contra a autoridade, seja ela jurídica, médica ou política, pois se afasta do caminho reto e ascendente traçado pela civilização. Nesse sentido, quem ousa transgredir os valores sociais instalados pela elite centro-europeia, cristã, capitalista e colonialista torna-se um desviado. O político não é algo que envolve apenas o Estado ou a luta de classes, mas atravessam também as relações sociais que condicionam a sexualidade, os discursos que regem a representação de gênero, as hierarquias raciais e as instituições que regulam o saber: a medicina, o

\footnotetext{
${ }^{6} \mathrm{Na}$ América Latina são chamados de diferentes maneiras, na Venezuela são güinches; na Colombia chanda; na Argentina são callejeros, cruza por calle ou raza perro; na Bolivia são rawe, chapi ou cachuchín; e no Brasil vira-lata.
} 
direito, o sistema educativo, etc. Com Michel Foucault aprendemos que existe uma relação indissociável entre saber e poder. Segundo o autor, não se pergunta o que é ou não é a verdade, mas deve-se procurar quais são os pré-requisitos, em determinadas condições históricas, que estabelecem que algo seja instalado como uma verdade. Foucault nos faz abre os olhos para mostrar que toda verdade, assim como toda instituição, é um dispositivo poderoso, cuja função é nos submeter. E embora os submetidos não tenhamos muitas saídas, ainda podemos contar com a subversão, a fuga, a mutação ou o transformismo.

A modernidade colonialista implantou seus dispositivos de forma sistemática e para construir o sujeito sexual da modernidade. Fomos educados para compreender e classificar as sensações e o sentido das coisas dentro do marco da cultura hegemônica, ou seja, os seres humanos pensamos e construímos nosso mundo a partir de paradigmas dominantes que se constroem socioculturalmente. Da mesma forma, a construção da subjetividade sexual ocorre a partir de dispositivos semióticos que são moldados e construídos historicamente. Em História da Sexualidade7, Foucault propõe que o sujeito sexual moderno é constituído por um conjunto de instituições disciplinares. Essas instituições, que surgem no século XIX sob a influência da ciência positivista, do darwinismo e do racismo, criaram um conjunto de paradigmas sociais que ainda hoje nos colonizam. São sistemas políticos de produção de verdade, que segundo um conjunto de discursos e imagens condenam, de forma decisiva, o que é verdadeiro ou falso, legítimo ou ilegítimo, saudável ou doentio.

Na segunda metade do século XIX, com o fim do conflito entre a burguesia e a nobreza, o mundo inteiro tornou-se capitalista. É o momento em que os Estados nacionais foram inventados e começaram os processos de expansão colonial das nações industrializadas da Europa. O resultado foi a violenta política colonial impulsada por capitalistas financeiros que se associavam aos poderes políticos de seus Estados para incorporar novos territórios nos quais investir, vender seus produtos e conseguir matérias primas e mão de obra barata quando não gratuita. Este processo foi possível porque o ciclo revolucionário se encerrou e a burguesia, que já concentrava todo o poder, deu uma guinada ideológica: deixou de ser revolucionária e passou a ser conservadora. Se antes havia sido uma força desestabilizadora, a partir de agora terá interesse em resguardar a ordem para se dedicar ao desenvolvimento do que fora seu projeto político: produzir bens de consumo. A burguesia renuncia ao iluminismo e abraça um positivismo promovido por intelectuais orgânicos como Augusto Comte, que afirmava: "O amor como princípio, a ordem como base e o progresso como meta". ${ }^{8}$

\footnotetext{
${ }^{7}$ FOUCAULT, Michel. Historia de la sexualidad 1. La voluntad de saber. México: Siglo XXI, 1987.

8 "L'Amour pour principe; L'Ordre pour base, Et le Progrès pour but" (tradução nossa). COMTE, Auguste, Système de politique positive, ou traité de sociologie, Instituant la Religion de l'humanité, Tome premier. Paris: imprimé par e. Thunot et $\mathrm{C}^{\circ}$, p. 9. Disponível em: https://babel.hathitrust.org/cgi/pt?id=uc1.aao001525567\&view=1up\&seq=9. Acesso em: 7 dez. 2021.
} 
Desse modo, é no século XIX que a heterossexualidade passa a ser o regime estético-político hegemônico. O dispositivo disciplinar que tem como consequência a industrialização da sexualidade é a heterossexualidade patriarcal. Diante disso, o corpo homossexual, o corpo que se masturba ou o corpo fetichista tornam-se corpos desviados, que, como os colonizados, indígenas, asiáticos ou negros, tornamse corpos indesejáveis na confirmação das cidadanias nacionais. O melhor exemplo disso são os processos de branqueamento da população, que em alguns países se tornou um projeto político.

A colonização, em sua busca por mão-de-obra obediente, exigia submeter vastas populações as lógicas reprodutivas capitalistas. No entanto, em todo o mundo se deparava com grupos humanos habituados a uma ampla variedade sexual. Portanto, forçar os povos colonizados ao binômio heterossexual fazia parte de uma campanha disciplinar em favor da obtenção de trabalhadores dóceis à exploração. Como podemos perceber o sexo não só funciona como norma, mas também faz parte das políticas reprodutivas voltadas para a produção de corpos domesticados. O binômio heterossexual é um dispositivo produtivo que tem o poder de rotular, circunscrever e diferenciar os corpos que controla. Essa construção, que é um ideal regulatório, se materializa ao longo do tempo por meio de práticas altamente controladas; não é simplesmente uma realidade ou a condição estática de um corpo, mas o resultado de um processo no qual as normas regulatórias são posicionadas e legitimadas por meio da reiteração forçada.

O que constitui o caráter fixo do corpo, seus contornos, seus movimentos, é totalmente material, mas de uma materialidade que surge como o efeito mais produtivo do poder. Uma vez compreendida a operação que regula o sexo, a materialidade do corpo não pode mais ser concebida independentemente dela. Oyèrónkẹ Oyěwùmí a firma que foi a colonização inglesa que introduziu as categorias de gênero na sociedade yorubá, na Nigéria. Acontece que no território yorubá a mulher não existia; isso surgiu como efeito da colonialidade da episteme ocidental. Na episteme yorubá, a diferença entre os corpos era dada pela idade, não pela genitalidade.

Foi também a disponibilidade de mão de obra à necessidade que condicionou o outro objetivo central da biopolítica colonialista do século XIX: o controle da reprodução. Como resultado dos processos de industrialização, se estabelece uma estreita relação entre sexualidade e reprodução, e toda prática não reprodutiva passa a ser considerada patológica. Trata-se do que Paul Preciado ${ }^{10}$ chama de taylorização dos corpos, onde as mulheres, como máquinas reprodutivas, possibilitam os processos de expansão e colonização capitalista. Nessas circunstâncias, o corpo da mulher é semiotimizado como peça-chave na

\footnotetext{
${ }^{9}$ Cf.: OYĚWÙMÍ, Oyèrónkẹ. La invención de las mujeres. Una perspectiva africana sobre los discursos occidentales del género Bogotá: en la frontera, 2017

${ }^{10} \mathrm{Cf}$.: PRECIADO, Beatriz. Testo yonqui. Madrid: Espasa Calpe, 2008
} 
linha de produção, onde cumpre uma dupla função: produtora e reprodutora. Incluído na linha de produção fordista, o corpo da mulher é disciplinado para entrar em agenciamento com as demais máquinas envolvidas nos processos de produção industrial.

Para chegar à origem dessa estética política da diferença sexual, onde a família patriarcal heterossexual se constitui como base da sociedade, e onde a masculinidade e a feminilidade se apresentam como verdades anatômicas foi necessário, em termos foucaultianos, um arquipélago disciplinar conforme com os dispositivos científicos do século XIX: o hospital, o museu, a prisão, o manicômio e principalmente a escola. No entanto, essa imposição nunca esteve isenta de resistência. Uma das críticas mais notáveis é a de Simone de Beauvoir ${ }^{11}$, quando afirma em 1949 que a episteme ocidental se equivoca ao dar como certo que a "biologia é destino". Para ela, as características das mulheres e dos homens não podiam ser explicadas a partir de determinantes biológicos. Então, as feministas da segunda onda da década de 1970, acrescentaram mais argumentos para demonstrá-lo. Argumentaram que as diferenças entre homens e mulheres são produzidas por uma série de instituições sociais destinadas a perpetuar a desigualdade, e que mesmo quando homens e mulheres cumprem funções reprodutivas diferentes, a maioria das diferenças não vem de determinantes biológicos, mas são dadas por relações sociais.

Assim, o sexo não é uma categoria puramente física; os sinais e funções corporais que definimos como masculinos ou femininos estão incluídos em nossas concepções de gênero. Por exemplo, em casos de bebês sexualmente indefinidos, os médicos recorrem a cirurgias e tratamentos hormonais para legitimar sua decisão de intervir nesses corpos. A escolha dos critérios de determinação do sexo é, ao mesmo tempo, determinada por uma vontade articulada socialmente. Portanto, as decisões científicas não podem ser tomadas como guias absolutas. As verdades sobre a sexualidade humana elaboradas por intelectuais, em geral, e biólogos, em particular, segundo Anne Fausto-Sterling ${ }^{12}$, fazem parte dos debates políticos, sociais e morais sobre nossas culturas e nossas economias, mas verdades que se incorporam de uma forma muito literal para o nosso ser fisiológico.

Anne Fausto-Sterling destaca que a intelectualidade está implicada nos processos de formação do sexo e gênero. Fausto-Sterling explora a maneira em que os cientistas criam verdades que afetam o corpo de todes nós. Verdades que são construídas a partir de experimentos e práticas que não podem ser dissociadas do ambiente cultural em que os cientistas exercem sua profissão. O que eles pensam sobre como funciona o mundo molda o conhecimento que produzem os pensadores; e esse conhecimento, por

\footnotetext{
${ }^{11}$ Cf.: DE BEAUVOIR, Simone. El segundo sexo. Madrid: Cátedra, 2005.

${ }^{12}$ Cf.: FAUSTO-STERLING, Anne. Cuerpos sexuados. Barcelona: Melusina, 2006.
} 
sua vez, afeta o corpo. Portanto, se para David Halperin ${ }^{13}$ a sexualidade não é um efeito somático, mas um efeito cultural, para Fausto-Sterling a sexualidade é um fato somático criado por um efeito cultural.

Fausto-Sterling nega que haja um conhecimento indiscutivelmente fisiológico das ciências naturais com relação ao sexo; e outra, polêmica, opinável, cultural, pertencente às ciências sociais, que seria o gênero. Seguindo Judith Butler ${ }^{14}$, entende que a categoria sexo é desde um princípio normativa, o que Foucault chamou de ideal regulatório. Butler questiona a lógica heteronormativa, que propõe a complementaridade natural entre homens e mulheres, para ir ainda mais longe e questionar as categorias que naturalizam as definições dos corpos. Para Butler, os próprios corpos são uma construção cultural baseada por discursos científicos. Discursos que devem ser desarticulados, pois violam gravemente a diversidade dos desejos e identidades sexuais. A hegemonia heterossexual torna-se, então, nos termos de Monique Wittig ${ }^{15}$, um regime totalitário que infringe qualquer identidade que não esteja de acordo com os modelos que estabelece.

O gênero não é algo que está no corpo, na psique ou em qualquer tipo de essência, mas é algo performativo pois se constrói a partir de gestos ou atos cotidianos, como a maneira de falar, mover-se ou vestirse. Eé justamente essa performatividade de gênero que nos permite desarticular, a partir de ressignificações, sobre o que significa ser mulher ou ser homem. Desarticulação que Butler estende às identidades propostas pelos conceitos de raça ou nação.

A educação não é uma tecnologia neutra na modernidade colonialista-capitalista. O espaço pedagógico é um dispositivo de normalização e subjetivação do corpo, um espaço onde, além disso, se inventam e se reproduzem segmentações de sexo, gênero, classe, etc. Os dispositivos sexo-semióticos são tão eficazes que os próprios colonizados internalizam o discurso colonial e o reforçam quando dizem "sou heterossexual", "sou homossexual". Assim, a colonização ocidental não só alcançou a supremacia econômica à custa de nosso empobrecimento, mas também conseguiu nos identificar com seus dispositivos de normalização.

A hegemonia colonial patriarcal não apenas impõe sua estética visual da diferença sexual, mas também a naturaliza. Mobilizam recursos e energias para manter esta performance que é realizada diariamente no espaço público. A performance da masculinidade ou feminilidade requer um conjunto de coreografias corporais, muitas vezes absurdas. Esse binário heterossexual que geralmente é assumido como universal nada mais é do que o resultado de um processo de padronização performativa, de um processo de reprodução performativo. De fato, se chegamos a pensar que nos adaptamos livremente à estética da diferença sexual, é porque o próprio corpo, por meio de taxonomias exaustivas, foi modelado como um aparelho disciplinar.

\footnotetext{
${ }^{13}$ Cf.: HALPERIN, David. San Foucault. Para uma historiografía gay. Buenos Aires: El cuenco de plata, 2007.

${ }^{14} \mathrm{Cf}$.: BUTLER, Judith. El género en disputa. El feminismo y la subversión de la identidad. Barcelona: Paidós, 2016.

${ }^{15} \mathrm{Cf}$.: WITTIG, Monique. El pensamiento heterosexual y otros ensayos. Madrid: Egales, 2006.
} 


\section{Uma revolução política dos corpos}

Contudo, existem corpos dissidentes que propõem estratégias para escapar dos sistemas disciplinares. Seu desafio é resistir à dominação heteronormativa, patriarcal, colonialista e neoliberal, opondo-se aos dispositivos disciplinares que produzem "verdades" e taxonomias rígidas, inventando metodologias críticas, consciências críticas e desenvolvendo estratégias de dissidência epistêmica para transformar a herança cognitiva capitalista. Decodificando os discursos do biopoder e criando novos conhecimentos episteme, esses corpos estão desarticulando as imposições do capitalismo colonial. Acima de tudo, atacando o coração do conhecimento episteme normativo: a educação. Então, ali onde a imagem havia sido o dispositivo predileto para a implantação de saberes hegemônicos, agora são introduzidos dispositivos mestiços e saberes subalternos que deslegitimam aquelas afirmações que se apresentavam como "verdades".

Experimentar novas formas de fazer política, ou micropolíticas, contradisciplinares e reinventar processos revolucionários é a luta que os corpos dissidentes vêm travando. Uma insurreição assumida por corpos cujo performance sexual altera a ordem da sociedade neoliberal, corpos que não querem se integrar em uma sociedade heteronormativa, mas buscam a inclusão a partir da emancipação sexual, cognitiva e política. Corpos que, para além das categorias LGTBIIQA+, são corpos sexualmente dissidentes, que se revelam na estreita relação entre sexualidade e reprodução. Eles não só promovem revoluções sexuais ou feministas, mas também movimentos de redefinição do corpo contra as práticas que definem como esse corpo é governado (os dispositivos disciplinares). O que Paul Preciado chama de povo múltiplo, esse povo de mutantes que se encarnam em fatos sociais, literários, artísticos, musicais, etc. Já não uma internacional proletária, mas uma internacional multiforme de mutantes.

O poder é atacado porque quem o tem não quer perdê-lo. O contrato social pode ser modificado, desconstruído, pensado de outra maneira, visto de outro modo. Assim, a estética camp articula a combinação entre o andrógino e a extravagância, bem como o distanciamento do que é imposto como "natural". Fortemente enraizado no espaço urbano, expressando-se a partir da teatralização, a sátira, a ironia, o lúdico o gozo estético, as problemáticas sobre os papéis de gênero e norma sexual, o camp surgiu como estratégia política/poética em meados da década de 1960.

De acordo com Halim Badawi e Fernando Davis ${ }^{16}$, a estética camp busca problematizar a heterossexualidade como estrutura normalizadora, estabelecendo ao corpo um espaço de resistência e

\footnotetext{
${ }^{16}$ Cf.: BADAWI, Halim; DAVIS, Fernando. Desobediencia sexual. In: MUSEO NACIONAL REINA SOFÍA. Perder la forma humana. Una imagen sísmica de los años ochenta en América Latina. Madrid: Museo Nacional Reina Sofía, 2013.
} 
insubordinação que "trastorna la coherente estabilidad de la relación sexo/género y sus asignaciones identitarias fijas, según la matriz de inteligibilidad heterosexual”17. A partir de 1990, uma mutação derivada de problemas homossexuais e de liberação é gerada gradualmente, e o camp faz um giro para a teoria Queer (kuir, cuir). A partir desse momento, a desobediência sexual e a visibilidade dos corpos dissidentes se radicalizam. As minorias valorizam sua diferença indagando sobre a visibilidade da diversidade a partir de abordagens políticas, sexuais, de identidade e/ou corporais. A partir deste ponto de vista, Valentina Pacheco e Ronny Vega propõem suas obras, da mesma forma que outros artistas plásticos chilenos têm feito, como Sebastián Cherrë, Sebastián Calfuqueo, Zaida González, German Bobe, o Coletivo Catrileo + Carrión, Felipe Rivas San Martín, Hija de Perra, Irina la Loca, entre outras.

O kuir não é apenas a ressignificação do insulto, é também uma objeção ao establishment de uma "cultura gay" baseada no consumo e uma resistência à adaptação do corpo à organização normativa heterossexual. O kuir busca eclodir as identidades, sejam de gênero ou sexuais, pois são rótulos que territorializam os corpos com estereótipos fixos e excludentes. A proposta política dos movimentos kuir é a desnaturalização da heterossexualidade, e denunciar a violência que esta exerce sobre corpos que não se enquadram em suas categorias normativas. Denunciando essa instabilidade, a visão kuir atual busca desconstruir as construções sociais que condicionam as anatomias, o gênero e a identidade sexual.

Conscientes do poder da imagem como um dispositivo semiótico, tanto o camp como o kuir usaram a mídia audiovisual para construir uma estética política da dissidência sexual. Em busca desse tipo de expressões, nos encontramos com a obra de Ronny Vega ${ }^{18}$ e Valentina Pacheco, ${ }^{19}$ dois artistas plásticos da cidade de Temuco, cujas imagens refletem essa resistência e desobediência sexual da qual falamos. Em uma lógica estética que transita entre o camp e o kuir, suas obras funcionam como dispositivos visuais de resistência. Afastando-se do cânone, colocam em cena imagens de corpos nos quais subjazem premissas contraculturais que

\footnotetext{
${ }^{17}$ Ibidem, p. 92.

${ }^{18}$ Ronny Vega (Temuco, Chile, 1992). É licenciado em Artes Visuais, na Universidade Católica de Temuco. Como artista visual exibiu em diversas exposições coletivas: Em 2015, (Anti)cuerpo, Centro Cultural de Padre Las Casas, Chile. Em 2016, Arte e VIH, Centro Cultural Rogelia, Santiago, Chile. Como membro do Colectivo 9, em 2017, circulou a exposição Visiones del paisaje, nos centros culturais municipais de Angol, Victoria, Padre Las Casa y Lautaro, na região de La Araucanía, Chile. Nesse mesmo ano expõe na Muestra colectiva de Exámenes de Grado na Galería de Arte da Universidade Católica de Temuco. Em 2018 expuseram Frontera: cuerpos y paisajes subversivos, na Galería de Arte da Universidade Católica de Temuco. Em 2020, adjudicou o Fondo Araucanía cultural digital da Municipalidade de Temuco, Chile com o qual produziu o vídeo de ensaio Río Kautín. Nesse mesmo ano também participa criando ilustrações para a publicação do livro de contos, Éramos niños, de Pablo Ayenao e dirigir a curtametragem infantil Tue Tue com a Companhia de Dança Plataforma Azul, projetos financiados com dos fundos Activarte da Corporação Cultural de La Araucanía. Em 2020, ainda, publicou uma resenha sobre poesia na revista La Juguera Magazine, Valparaíso, Chile.

${ }^{19}$ Valentina Pacheco (Santiago, Chile, 1993). Formou-se, em 2017, em Artes Visuais, na Universidade Católica de Temuco. Como artista visual exibiu em duas exposições coletivas: em 2016 no Festival de Arte Erótico de Santiago e em 2017 na Muestra colectiva de Exámenes de Grado na Galería de Arte da Universidade Católica de Temuco.
} 
se opõem aos modelos do consumismo neoliberal, modificados com photoshop, que territorializam o espaço público por meio da saturação abusiva.

A obra de Ronny Vega exige que o espectador observe seu próprio corpo e entenda que aquelas imagens promovidas pelo mercado são idealizações que nos deixam presos nos paradigmas do consumo. Em No se nace mujer, une llega a serlo, realizada em 2015 [Figura 2], nos coloca frente a um jogo no qual a obra opõe o bordado, uma prática própria do feminino, à "masculinidade" da pintura, enquanto prática majoritariamente realizada por homens. A ironia camp desta operação visibiliza uma incoerência relacionada aos cânones de comportamento social que se espera de um homem. desvela uma incompatibilidade nos cânones do comportamento social que se espera de um homem. Em Devoción [Figura 3], o kuir nos apresenta como aquela hipérbole grotesca, despreocupada e estridente que é o insulto transformado em identidade. Também encontramos esta mesma representação em (Des)modelado\#4 e \#5 [Figuras 4e 5], realizadas durante o ano de 2016.

As imagens de Valentina Pacheco aludem àquele antigo fascínio que o transgênero produz em nós [Figuras 6, 7, 8 e 9]. Embora a subjetividade transexual seja construída à margem da racionalidade dominante, cada vez que estamos diante dela, a certeza de nossa identidade sexual é desestabilizada. Essas imagens nos desafiam com um erotismo que vai à contramão dos códigos invisíveis que determinam os caminhos corretos do desejo, mas ainda assim nos seduzem. Esse estímulo nos convida a rever nossa relação com os regimes que constituem as verdades do desejo. Esses corpos "degenerados" em que barbas se combinam com seios ou seios com pênis produzem rejeição? Parece que nem tanto se nos referirmos aos fatos, por exemplo, a popularidade de programas como RuPaul's Drag Race, nos Estados Unidos, ou The Switch, no Chile.

A obra de Valentina Pacheco e Ronny Vega se relaciona com as formas em que corpo, objeto e alvo do poder, resiste à opressão que está por trás de sua forma subjetiva. A novidade de seus trabalhos é criar um imaginário que encene a radicalização dessas estratégias. Mais que um sujeito em uma posição transcendental, nos propõem focar nas múltiplas possibilidades sexuais do corpo e na variedade de forma que as identidades subversivas podem assumir.

Foucault ${ }^{20}$ afirma que o poder sempre circula através de dispositivos de todo tipo (jurídicos, linguísticos, científicos etc.), que não tem ponto central, mas é um acúmulo de dispositivos nos quais os sujeitos se envolvem. Entendemos essas ideias como um apelo para rejeitar as fórmulas universais, por vazias, e atentarmos para a análise dos dispositivos, das tecnologias envolvidas, das práticas e processos de subjetivação que a dominação utiliza para subjugar os corpos.

\footnotetext{
${ }^{20}$ Cf.: FOUCAULT, Michel. Microfísica del poder. Madrid: La Piqueta, 1978.
} 


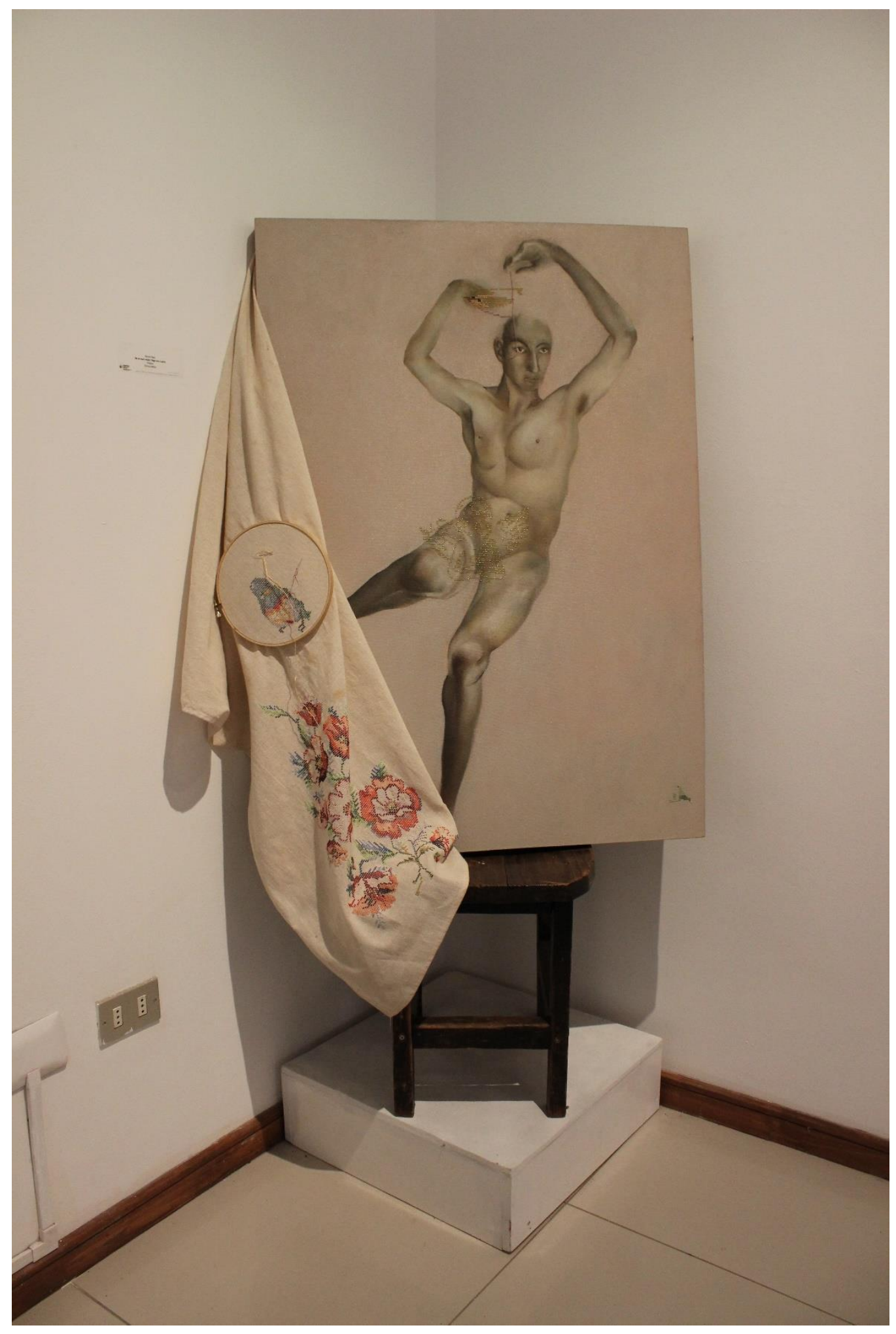

Figura 2:

Ronny Vega (Temuco, Chile, 1992). No se nace mujer, une llega a serlo

2015

Óleo e bordado sobre tela, $70 \times 90 \mathrm{~cm}$ Coleção do autor. Crédito da foto: Ronny Vega. 


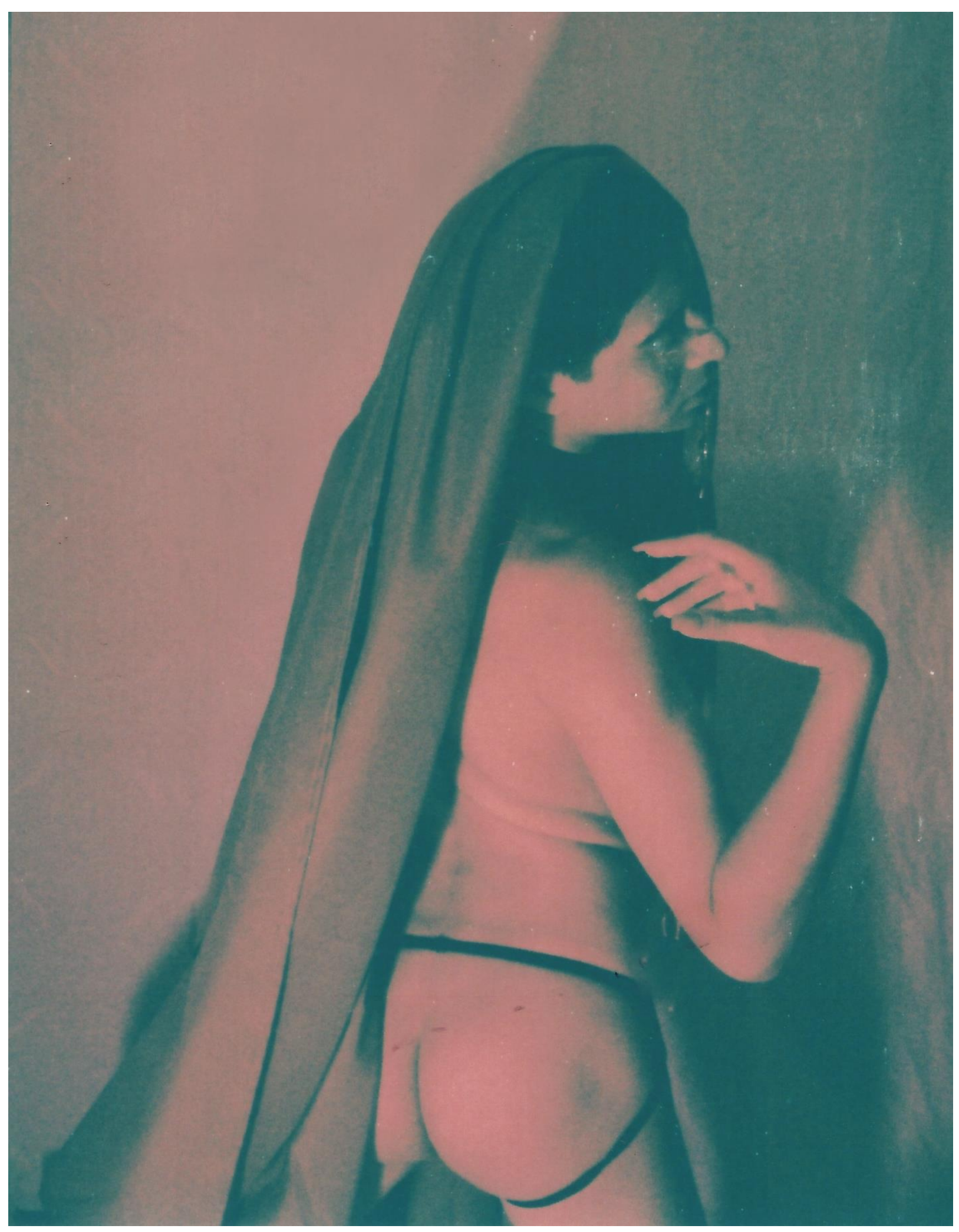

Figura 3:

Ronny Vega (Temuco, Chile, 1992)

Devoción

2016

Fotografia analógica, $70 \times 90 \mathrm{~cm}$.

Coleção do autor.

Crédito da foto: Ronny Vega. 

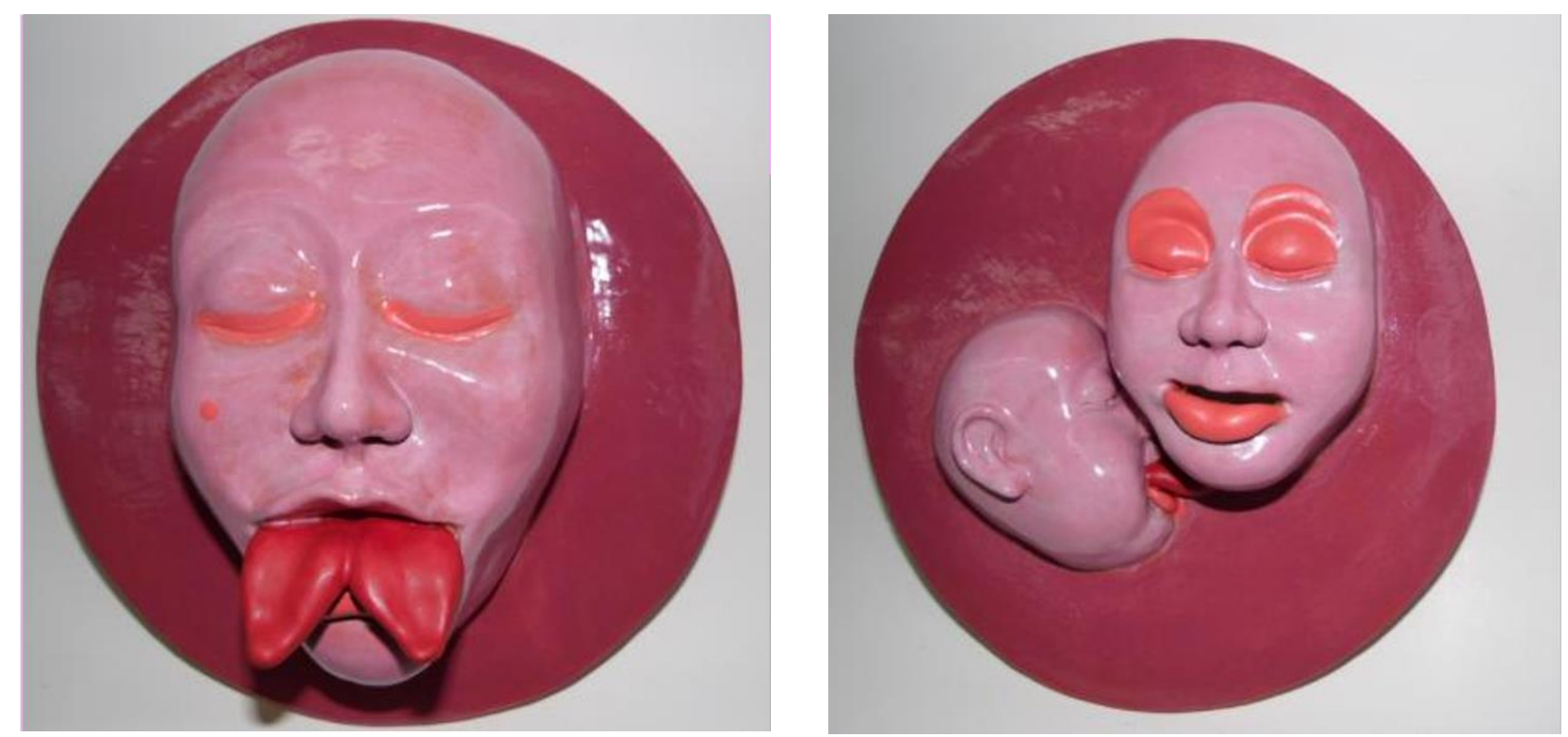

Figuras 4 e 5 :

Ronny Vega (Temuco, Chile, 1992)

(Des) modelado \#4 e \#5

2016

Cerâmica, $35 \mathrm{~cm}$ de diâmetro

Coleção do autor.

Crédito da foto: Ronny Vega.

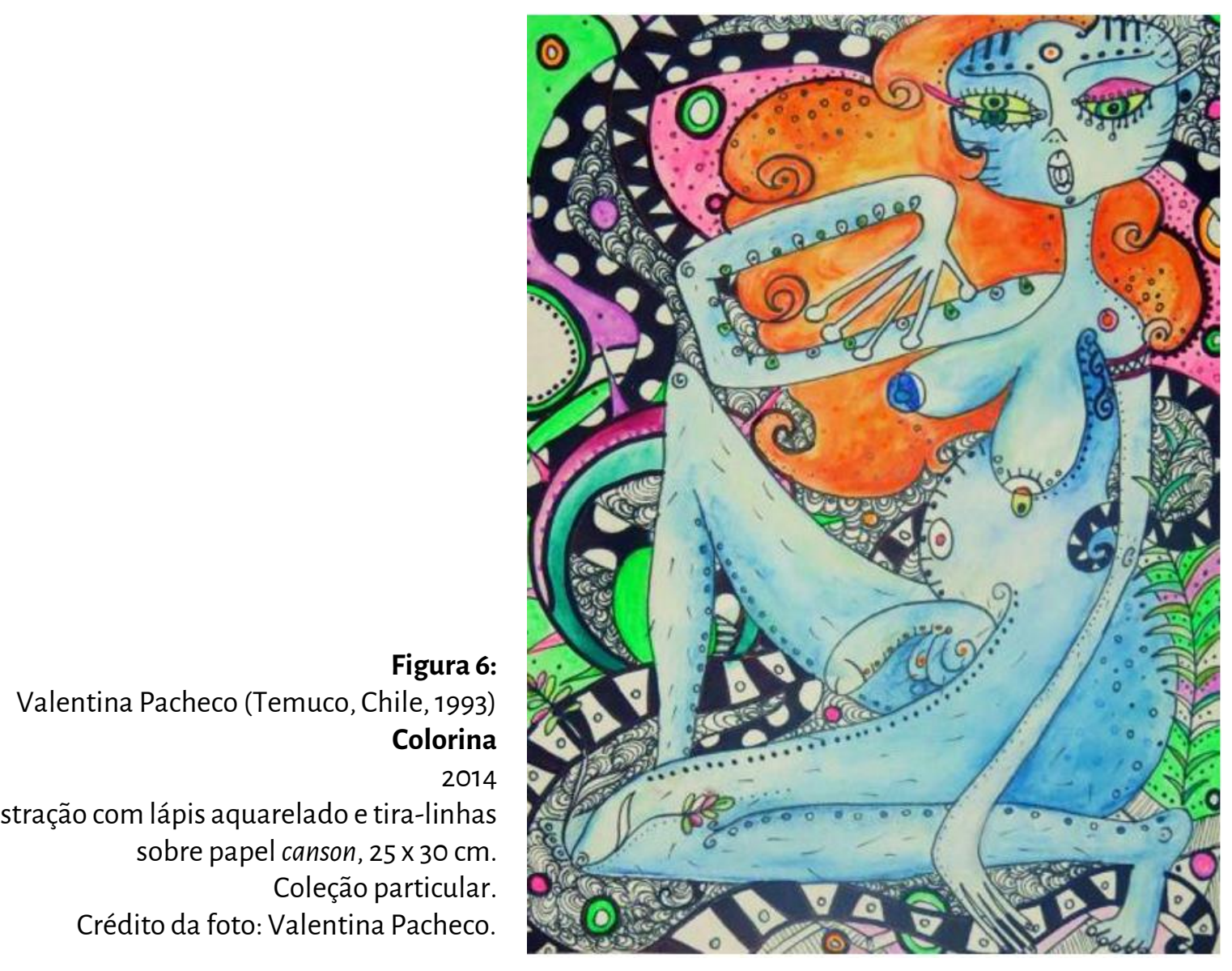


Figura 7:

Valentina Pacheco (Temuco, Chile, 1993)

Serie: Andróginos

2016

Ilustração com lápis aquarelado e tira-linhas sobre papel canson. Coleção da autora. Crédito da foto: Valentina Pacheco.

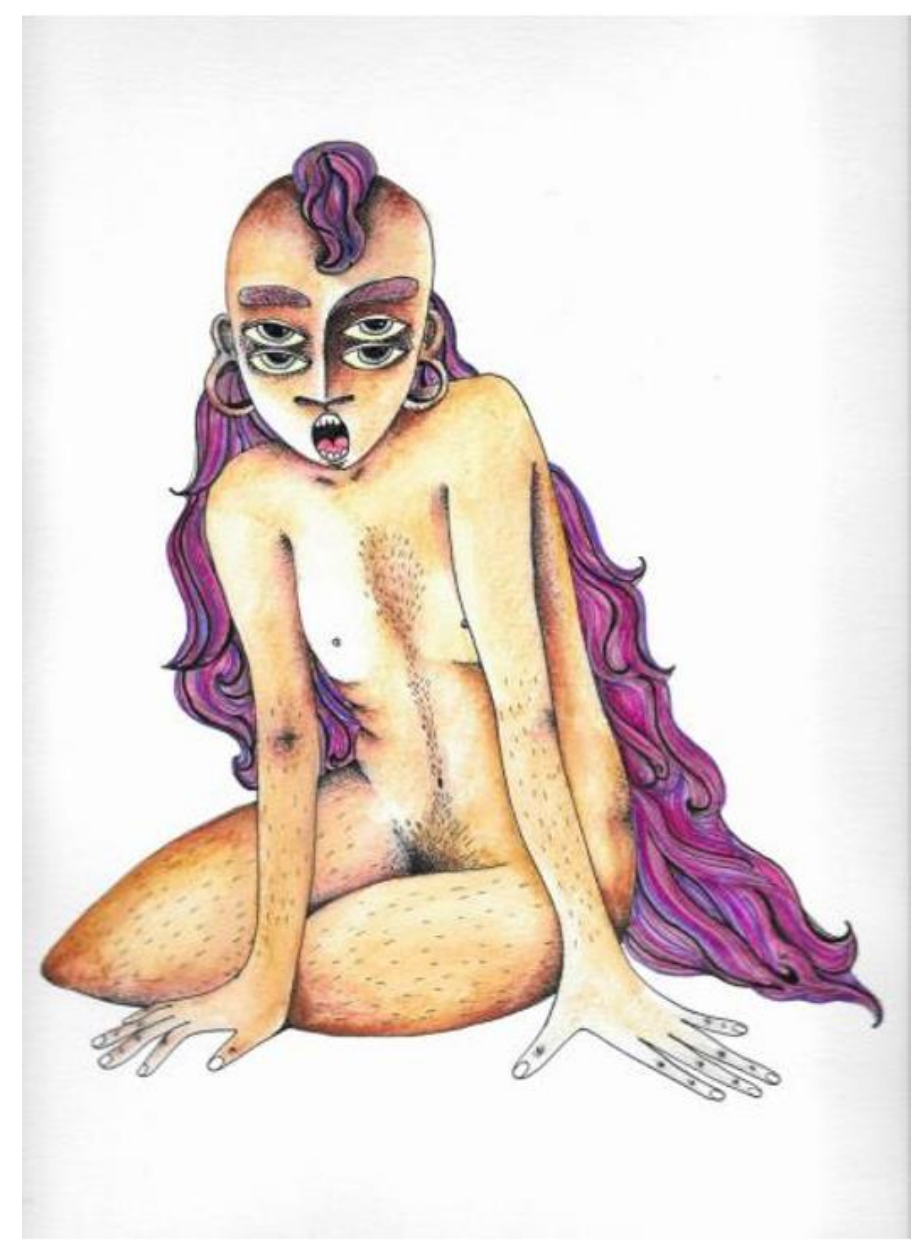

Figura 8:

Valentina Pacheco (Temuco, Chile, 1993)

Sin título

2016

Ilustração com lápis aquarelado e tira-linhas sobre papel canson. Coleção da autora.

Crédito de la foto: Valentina Pacheco.

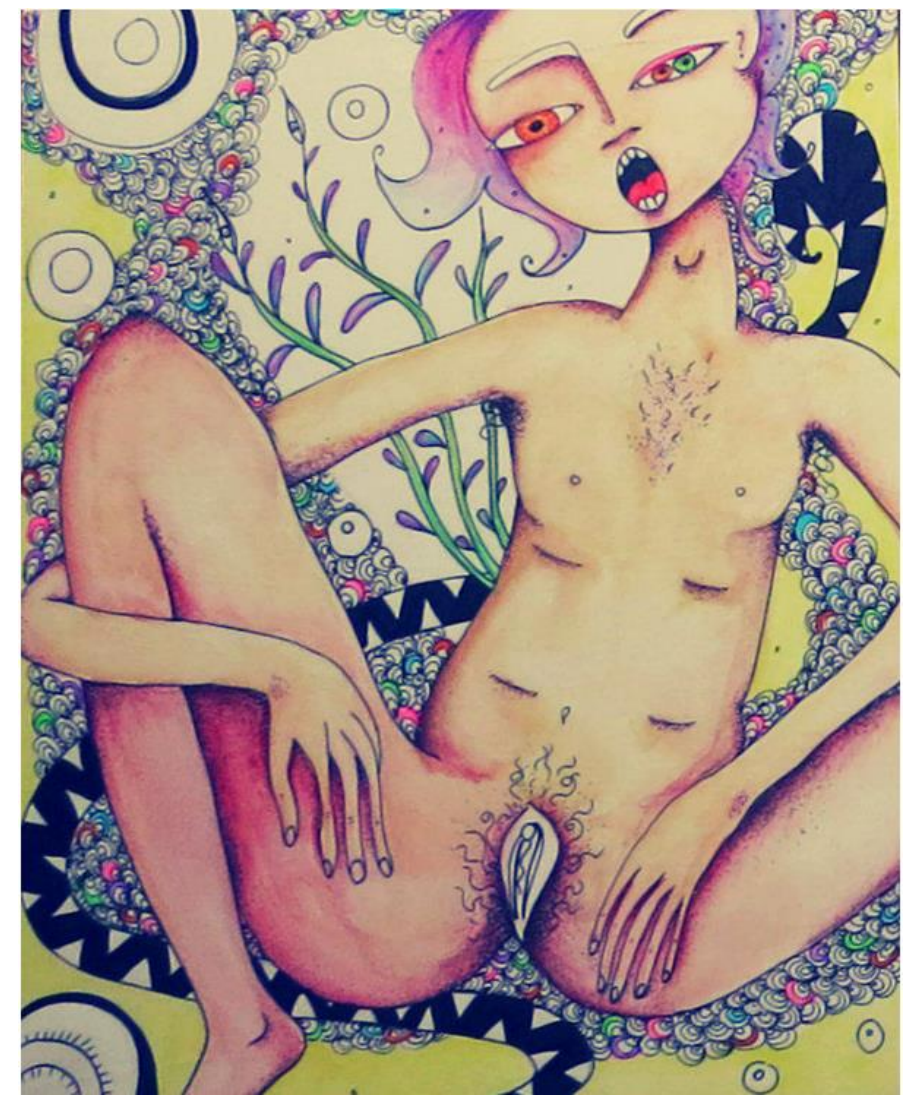




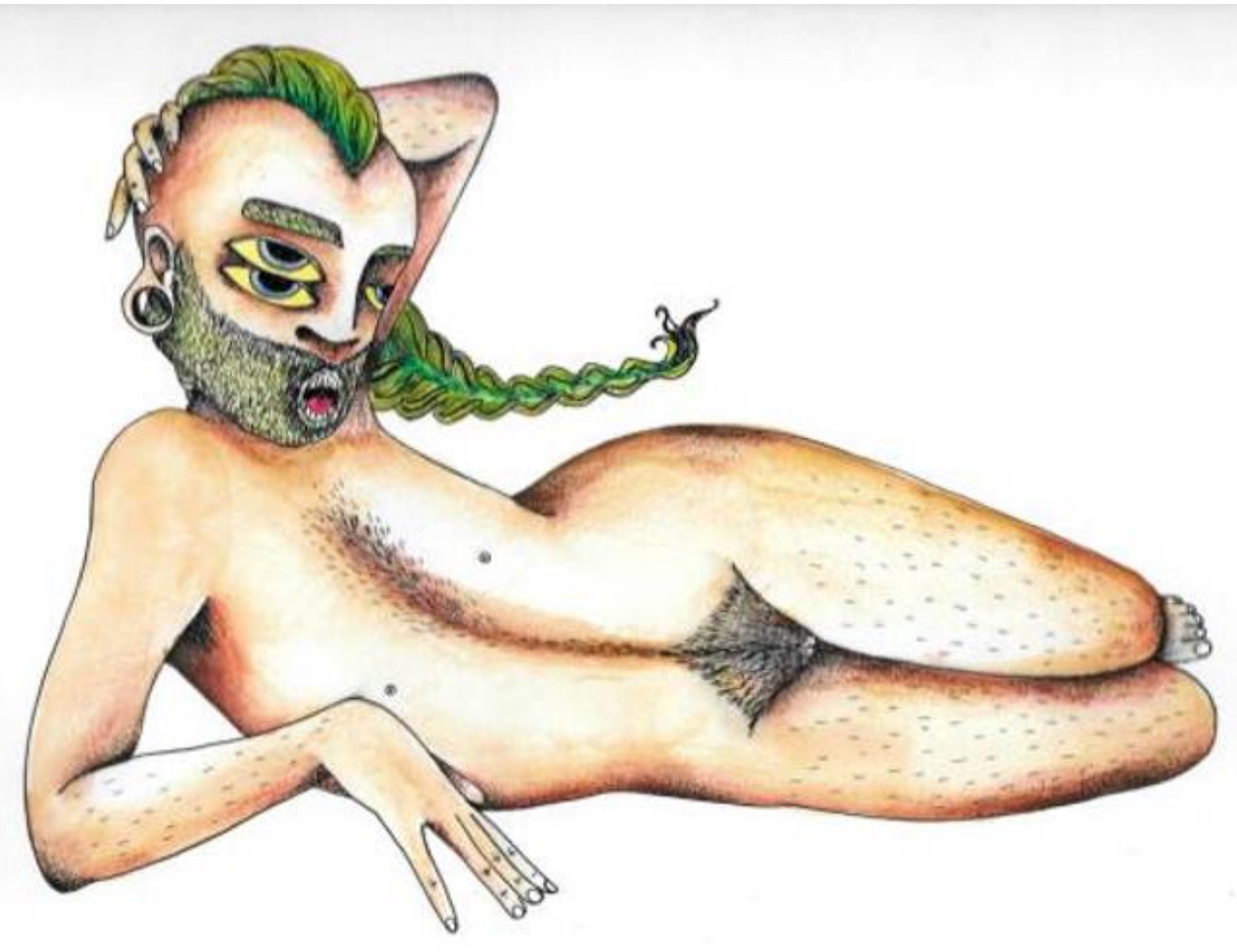

Figura 9:

Valentina Pacheco (Temuco, Chile, 1993)

Serie: Andróginos

2016

Ilustração com lápis aquarelado e tira-linhas sobre papel canson.

Coleção da autora.

Crédito da foto: Valentina Pacheco.

\section{Considerações finais}

Todo corpo abriga potencialmente resistências e capacidades para fugir do disciplinamento que vigia, submete e homogeneíza as corporalidades, para romper com as relações sociais estabelecidas pela norma e pelos discursos que as legitimam, e para criar corporalidades que se emancipam dos dados biológicos, anatômicos, fisiológicos, emocionais, culturais etc. Portanto, não é tão difícil que o rígido binômio heteronormativo no qual se relacionam a maioria dos corpos seja substituído por uma interação neutra que esteja não subordinada aos preconceitos, suposições e expectativas a priori determinadas pela mentalidade hegemônica.

A desobediência sexual, a emancipação do próprio corpo como território de resistência, a reivindicação de diferentes corporalidades ou a arte que se baseia em plataformas teóricas subversivas são formas de oposição ao colonialismo ocidental, cristão, capitalista, branco, heterossexual, machista, patriarcal e racista. 